\title{
Supplier evaluation: The first step in effective sourcing
}

\author{
Authors: \\ Kateřina Pikousová ${ }^{1}$ \\ Petr Průša ${ }^{1}$ \\ Affiliations: \\ ${ }^{1}$ Department of Transport \\ Management, Marketing \\ and Logistics, University of \\ Pardubice, Czech Republic \\ Correspondence to: \\ Kateřina Pikousová \\ Email: \\ katerinapikousova@seznam. \\ $\mathrm{Cz}$ \\ Postal address: \\ Břežany 128, Netvořice \\ 25744, Czech Republic \\ Dates: \\ Received: 03 Dec. 2012 \\ Accepted: 28 June 2013 \\ Published: 21 Oct. 2013 \\ How to cite this article: \\ Pikousová, K. \& Průša, P. \\ 2013, 'Supplier evaluation: \\ The first step in effective \\ sourcing', Journal of \\ Transport and Supply Chain \\ Management 7(1), Art. \\ \#87, 4 pages. http://dx.doi. \\ org/10.4102/jtscm.v7i1.87

\section{Copyright:} \\ (C) 2013. The Authors. \\ Licensee: AOSIS \\ OpenJournals. This work \\ is licensed under the \\ Creative Commons \\ Attribution License.
}

Read online:
The evaluation and selection of suppliers are important tasks in any organisation. Each organisation needs to have a supplier evaluation matrix or model in place. The goal of this article is not only to give an overview of supplier performance evaluation techniques but also to present an example of such a supplier evaluation matrix used in practice. The article shows that suppliers' qualities, strategies and abilities affect a buying company's business. Reliable suppliers can help to develop stabile, long-term relationships that will be beneficial to both parties. Effective sourcing and purchasing require high-quality suppliers.

\section{Introduction \\ Problem statement}

Supplier evaluation is an issue of strategic importance for any company. Measuring supplier performance is essential to ensure a well-functioning supply chain and company competitiveness. The goal is to improve performance mainly of the key suppliers. Understanding supplier performance will both prevent risk and improve cooperation. Evaluation is necessary to know what the supplier is doing well in each area of action. Careful selection of evaluation criteria is important.

\section{Background and trends}

There have been many approaches to evaluating supplier performance. Previously, supplier evaluation criteria focused on delivery performance, quality and price. Today, we see both in practice and in literature several criteria focusing on other areas, such as relationship of partners and continuous improvement.

\section{Objectives}

This article discusses some of best practices currently in use and point out the importance of the supplier evaluation theme. The goal is not to find the perfect supplier evaluation matrix, but to find the set of indicators used most often for supplier performance evaluation. The article presents a review of a number of articles relating to supplier performance as well as a case study of an existing company's supplier performance and its details of calculation.

\section{General supplier evaluation}

The majority of supplier evaluations consist of only three factors: price, quality and delivery (Hirakubo \& Kublin 1998; Howard 1998). Degraeve and Roodhooft (1999) argued that supplier selection and evaluation are most often based on price, which, in turn, results in additional costs to the buyer because of unreliable delivery, limited quantities, inferior quality and inadequate communication.

According to a study on the evaluation processes of the supplier (Simpson, Siguaw \& White 2002) only a limited number of buyers have a formal supplier evaluation process in place. This is an important finding as suppliers can influence the inventory status of a company on a high level.

Supplier selection has to be first step. Selection of the supplier plays a role in profitability and companies should pay attention to the selection when awarding contracts. According to Jayaraman, Srivastava and Benton (1999) the selection of a new supplier may result in additional fixed costs as a company may have to invest in new machinery, staff training or implementing new technologies.

\section{Multicriteria decision-making techniques for supplier evaluation}

In a situation where one supplier provides goods at low rates but is unable to deliver on time whilst another provides high-quality goods but at unacceptable prices, a company has to use 
appropriate supplier selection techniques. Supplier selection is an issue related to the multicriteria decision-making (MCDM) problem. Numerous evaluating criteria have to relate to the requirements of the company. Therefore, it is crucial to analyse and prioritise different selection methods to satisfy stakeholders. Using methods such as data envelopment analysis and analytical hierarchy processes, a company can evaluate suppliers for optimal selection. The chosen approach has to be company specific, as each company has to identify the most important criteria for selecting the best supplier based on company strategy, industry type and needs.

Researchers use different methodologies of MCDM to solve supplier evaluation and selection problems. According to Agarval (n.d.) data envelopment analysis is the most often used MCDM approach (30\%), followed, in order of distribution, by mathematical programming $(17 \%)$, analytical hierarchy processes (15\%), case-based reasoning (11\%), fuzzy set theory $(10 \%)$ and analytical network processes $(5 \%)$. It is evident that cost alone is no longer the leading criterion driving supplier selection. Instead, quality and delivery performance also are contributing factors. Many evaluation criteria can arise from the requirements of the company. It is important to analyse and prioritise various evaluation methods to select the most appropriate one. Applying methods such as the aforementioned, we can assess suppliers for optimal supplier selection. Agarval et al. (n.d.) concluded that analytical hierarchy processes can be used as a helpful tool for evaluating suppliers.

\section{Key performance indicators}

Key performance indicators are quantifiable measurements, agreed to beforehand, that reflect the critical success factors of an organisation. They should reflect the organisation's goals, contribute to its success and be measurable. Key performance indicators are usually long-term considerations. Their definition and how they are measured do not change often. The goals for a particular key performance indicator may change as the goals of the organisation change or as the organisation approaches its goals.

\section{Common indicators of supplier performance matrix}

In supply chain management, the buyer-supplier relationship is critical to achieving the strategic goals of a company. Supplier evaluation processes can be both formal and informal and matrices are an important tool in determining the long-term success of a company.

\section{Results}

Each company performs its own supplier evaluation. Large multinational companies deal with supplier evaluation on a much different level than small, local companies do. Long-term partnerships with suppliers are key to successful business, which emphasises the importance of supplier selection during sourcing.

Table 1 shows commonly used supplier evaluation areas of seven companies, together with the criteria used most often for evaluating supplier performance. Sophisticated systems for supplier evaluation depend on the strategy and philosophy of the specific company. Large companies operating abroad generally have highly developed sourcing systems as the partnership with their suppliers is a long-term one and crucial to their operations.

Following from the criteria presented in Table 1, four criteria are used most often and the associated key terms used in measurement could be derived (Table 2).

\section{Reliability and validity}

Quality is one of the main criteria in supplier performance. Well-organised and applied procedures for quality planning include the use of quality methods such as failure mode and effects analysis, capability testing, certification by the International Organization for Standardization and ensuring that customers are satisfied. Evaluation depends partly on how set targets are met and how supplier output relates to best practices.

Delivery is the application of logistic management. Delivery refers to the precision, service level and control during distribution of goods. Evaluation of delivery includes assessment of the supplier's ability to meet the requirements for on-time deliveries and ordered quantities and a buyer should have an appropriate system in place for effective assessment.

Price is the first and the last criterion when deciding to award business to a supplier. Each response to an offer starts with the price. When evaluating suppliers, criteria for price development, prices of current and future business, redistribution of current business, other savings and new distribution modes in case of extentions need to be considered.

TABLE 1: Supplier evaluation criteria used by different companies.

\begin{tabular}{lccccccc}
\hline Evaluation criterion & \multicolumn{7}{c}{ Company } \\
\cline { 2 - 8 } & A & B & C & D & E & F & G \\
\hline Company profile & - & - & - & - & - & - & - \\
Management & yes & yes & - & - & - & - & - \\
Overall situation & yes & - & yes & - & - & - & - \\
Competence & yes & yes & - & - & - & - & - \\
Company culture & - & - & - & - & - & - & yes \\
Price & yes & yes & yes & yes & yes & yes & yes \\
Production & yes & - & - & - & - & - & - \\
Quality & yes & yes & yes & - & yes & yes & yes \\
Level of claims & yes & - & yes & yes & yes & - & yes \\
Delivery security & yes & yes & yes & yes & yes & yes & yes \\
Cancelation ratio & - & - & - & yes & - & - & - \\
Lead time & - & - & - & yes & - & - & - \\
Price development & - & - & - & yes & yes & yes & yes \\
\hline
\end{tabular}

TABLE 2: Criteria used most often.

\begin{tabular}{ll}
\hline Criterion & Key terms used for measurement \\
\hline Quality & Product; process; systems; facility; people \\
Delivery & $\begin{array}{l}\text { Incoming material; production; work in progress; finished } \\
\text { goods; stock }\end{array}$ \\
Price & $\begin{array}{l}\text { Price deveopement; ongoing; redistribution; other savings, } \\
\text { new distribution modes }\end{array}$ \\
Claims & Cost of poor quality; undelivered goods; wrong spare parts \\
\hline
\end{tabular}


Claims refer to a non-conformance between the product and the requested quality based on approved technical documentation. Another reason for claims can be damage to the product during transport to the customer, incurred in any part of supply chain. Each claim decreases the profits of a company and therefore companies need to have many systems for monitoring, dealing with and reducing claims. Corrective actions are generally implemented.

\section{Logistic supplier performance: Case study of Company $\mathbf{X}$}

Supplier performance refers to whether a supplier is able dispatch products of the agreed quality on time. It is measured periodically. Supplier performance is a common indicator of logistic success. This indicator focuses on the supplier's lead time (handling time). Handling time or lead time generally refers to the average time from creating a task to its execution, which translates to the time from when an order is created to when it is fulfilled. This key performance indicator helps to determine how long it takes, on average, to handle requests.

The case study focuses only on logistic key performance indicators. Company $\mathrm{X}$ regularly assesses suppliers with regard to agreed lead time, average lead time, delivery security and cancelled value. Logistic performance indicators are shown in Figure 1, together with short explanations of each.

\section{Agreed lead time}

Agreed lead time is measured in days. This variable is calculated as the difference between the date of receiving the order and the originally planned dispatch date of the order, weighted in value (price of order).

\section{Average lead time}

Average lead time is also measured in days. It is calculated as the difference between the date of receiving the order and the planned dispatch date of the consignment, weighted in value (price of the order) for a fixed period.

For evaluating supplier performance it is necessary to compare the agreed lead time and the actual lead time, referred to as lead time accuracy. This is an indication of the supplier's ability to keep to the agreed delivery schedule.

\section{Delivery security}

Delivery security is an indicator of the extent of the delay between the planned dispatch date and the actual dispatch date, expressed as a percentage. When delivery security is at $100 \%$ it means that all the ordered goods have indeed been delivered by the planned date. Orders that are delivered after the planned dispatch date will decrease the delivery security; it follows that the bigger the delay, the lower the delivery security. The delay is weighted in value (price of the order). Data selection for this field is based on the planned dispatch date of the consignment.

$1 . C o m p a n y ~ X$ is used as a pseudonym to protect the identity of the company.

\section{Cancelation ratio}

The cancelation ratio expresses the number of cancelled orders relative to the number of originally ordered goods. Data selection for this indicator is based on the originally planned dispatch date.

Figure 2 shows that delivery security and the cancelation ratio do not necessarily follow the same trend. In contrast,

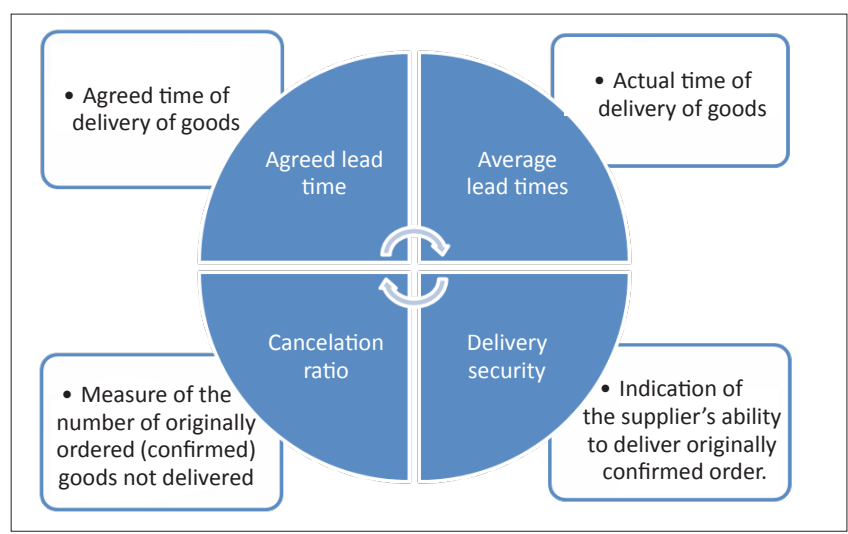

FIGURE 1: Logistic performance indicators used by Company X.

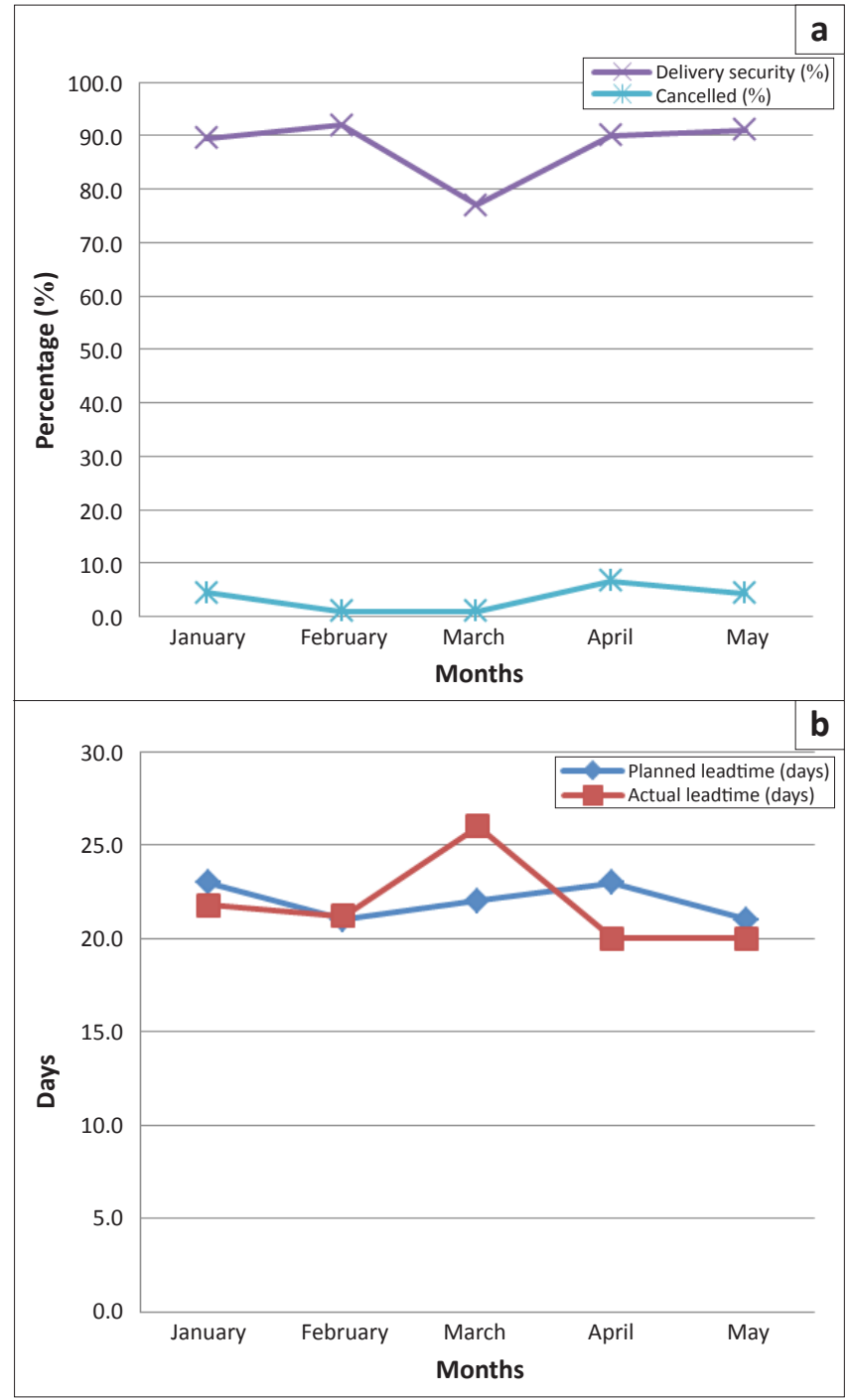

FIGURE 2: Actual indicator scores (a) in percentage and (b) in days, achieved by Company X between January 2011 and May 2011. 
TABLE 3: Details for calculation of logistic key performance indicators.

\begin{tabular}{lccccc}
\hline Key performance indicators & \multicolumn{5}{c}{ Month } \\
\cline { 2 - 6 } & January & February & March & April & May \\
\hline Planned lead time (days) & 23.0 & 21.0 & 22.0 & 23.0 & 21.0 \\
Actual lead time (days) & 21.8 & 21.2 & 26.0 & 20.0 & 20.0 \\
Diference & -1.2 & 0.2 & 4.0 & -3.0 & -1.0 \\
Delivery security (\%) & 89.5 & 92.0 & 77.0 & 90.0 & 91.0 \\
Cancelled (\%) & 4.4 & 1.0 & 1.0 & 6.7 & 4.3 \\
\hline
\end{tabular}

when suppliers fail to cancel orders that they were not able to dispatch, both a low cancelation ratio and a low delivery security are evident. If a supplier is unable to dispatch part of an order but cancels it on time, delivery security is not affected. To ensure a successful supplier-client relationship, it is important that the client should explain the nature of its business to the supplier so that both parties work to the same goal.

As shown by the example of Company X (Figure 2), the supplier experienced problems in March, which were not communicated to the customer. This resulted in low delivery security. If the supplier had comunicated the expected problems in advance, the customer (Company X) could have adjusted the ordering proccess and delivery security would not have been affected so dramatically. For example, when looking at the fulfilling of requested planned dates some differences can be seen (see Table 3) such as the supplier delivered goods four days later on average in March and prior to that, in February, it is almost exact as well.

\section{Conclusion}

Supplier performance evaluation provides a customer with a quantifiable measure and thus the status of the supplier and the possible influence a relationship with the supplier could have on its business' success. This article described criteria commonly used during supplier performance evaluation. The supplier evaluation is a way indicate the requirements and values, which are featured on the suppliers' development.
Closer cooperation, sharing common processes for setting targets (quality, delivery, price, claims, etc.) and implementing appropriate measurement systems foster stronger customersupplier relationships. Supplier evaluation therefore helps a company to establish a process for selecting suppliers and continuous evaluation of the selected suppliers, which allows a company to provide a responsive network of suppliers with respect to the company's objectives. The case study showed the mutual customer-supplier dependence on key performance indicators.

\section{Acknowledgments Competing interests}

The authors declare that they have no financial or personal relationship(s) that may have inappropriately influenced them in writing this article.

\section{Authors' contributions}

K.P. (University of Pardubice) was the project leader. Both K.P. and P.P. (University of Pardubice) were equally responsible for writing this article.

\section{References}

Agarwal, P., Sahai, M., Mishra, V., Bag M. \& Singh, V., n.d., 'A review of multi-criteria decision making techniques for supplier evaluation and selection', International Journal of Industrial Engineering Computations, viewed 11 November 2012, from www.GrowingScience.com/ijiec

Degraeve, Z. \& Roodhooft, F., 1999, 'Effectively selecting suppliers using total cost of ownership', Journal of Supply Chain Management 35(1), 5-10.

Hirakubo, N. \& Kublin, M., 1998, 'The relative importance of supplier selection criteria: The case of electronic components procurement in Japan', Internationa Journal of Purchasing and Materials Management 34(2), 19-24. http://dx.doi. org/10.1111/j.1745-493X.1998.tb00044.X

Howard, A., 1998, 'Valued judgements', Supply Management 25(3), 37-38.

Jayaraman, V., Srivastava, R. \& Benton, W.C., 1999, 'Supplier selection and order quantity allocation: A comprehensive model', Journal of Supply Chain Management 35(2), 50-58. http://dx.doi.org/10.1111/j.1745-493X.1999.tb00237.x

Simpson P.M., Siguaw, J.A. \& White, S.C., 2002, 'Measuring the performance of suppliers: An analysis of evaluation processes', Journal of Supply Chain Management 38(1), 29-41. http://dx.doi.org/10.1111/j.1745-493X.2002. tb00118.x 